\title{
PREPARATION OF MECHANICALLY ACTIVATED MIXTURES OF TITANIUM WITH THE CARBON NANOTUBES AND STUDY OF THEIR PROPERTIES UNDER THERMAL EXPLOSION
}

\author{
Sh.E. Gabdrashova ${ }^{1}$, N.M. Rakhova ${ }^{1}$, I.O. Pustovalov ${ }^{1}$, Zh. Elemesova ${ }^{1}$, M.I. \\ Tulepov $^{1}$, M.A. Korchagin ${ }^{2}$, L.R. Sassykova ${ }^{1, *}$, S. Sendilvelan ${ }^{3}$ \\ and D.A. Baiseitov ${ }^{1}$ \\ ${ }^{1}$ Faculty of Chemistry and Chemical Technology, al-Farabi Kazakh National University, 050040, \\ Almaty, Kazakhstan \\ ${ }^{2}$ Institute of Solid State Chemistry and Mechanochemistry, Siberian Branch of the \\ Russian Academy of Sciences, 630128, Novosibirsk, Russia \\ ${ }^{3}$ Department of Mechanical Engineering, Dr. M.G.R Educational and Research Institute, \\ University, 600 095, Chennai, India \\ *E-mail : larissa.rav@mail.ru
}

\begin{abstract}
The aim of the work was to study the effect of preliminary mechanical activation of titanium powder mixtures with the carbon nanotubes on a possibility of realization of the self-propagating interaction of reagents in the mode of dynamic thermal explosion and influence on phase composition and morphology of the formed products. It was found that after 2 min. mechanical activation, mechanocomposites of various sizes of irregular shape are formed, some of which are lamellar. There are no carbon nanotubes on the surface of titanium particles, which indicates their incorporation into the volume of mechanocomposites. The thermal explosion in activated samples of composition $\mathrm{Ti}+4 \%$ carbon nanotubes is realized starting from $1.5 \mathrm{~min}$ of mechanoactivation. The nature of the thermal explosion varies with the increase in the time of preliminary mechanical activation. After 3 min. of mechanoactivation in the sample at $346^{\circ} \mathrm{C}$, the preliminary smooth heat release starts at a temperature of $441{ }^{\circ} \mathrm{C}$, and a thermal explosion occurs, the maximum temperature is $930^{\circ} \mathrm{C}$. The phase composition of the products of the thermal explosion of the system under investigation is practically independent of the time of the preliminary mechanical activation. When the mechanical activation time is increased from 1.5 to 7 min., the products of the thermal explosion are titanium and titanium carbide.

Keywords: mechanoactivation, thermal explosion, titanium, carbon nanotubes, planetary ball mill

(C) RASĀYAN. All rights reserved
\end{abstract}

\section{INTRODUCTION}

With the introduction of the carbon nanotubes, the properties of materials and products from them change substantially ${ }^{1-4}$. At present, the efforts of scientists are mainly aimed at the development of composite materials reinforced with carbon nanotubes. The study of the structure, properties of composite materials containing carbon nanotubes has been devoted to many articles ${ }^{5-8}$. Of great interest is the introduction of carbon nanotubes (CNT) into metal matrices, such as $\mathrm{Cu}^{9,10}, \mathrm{Mg}^{11-13}, \mathrm{Al}^{14-17}, \mathrm{Ni}^{18-21}$. One promising material of the metal matrix is $\mathrm{Ti}$ and its alloys. The high specific strength of $\mathrm{Ti}$ and its alloys makes it possible to use them as technical materials with a low specific gravity and high strength. In order to improve the properties of $\mathrm{Ti}$ and to obtain new promising composite materials based on it, carbon nanotubes are added to the titanium matrix ${ }^{22-24}$. In recent years, there has been growing interest in combining mechanical activation of powder mixtures with methods of self-propagating synthesis. This is 
RASĀYAN J. Chem.

Vol. 11 | No. 1 |324 - 330 | January - March | 2018

due to the fact that the preliminary mechanical activation of powder mixtures makes it possible to significantly expand the possibilities for self-propagating synthesis of inorganic materials ${ }^{25-27}$.

In this regard, the aim of the work was to study the effect of preliminary mechanical activation of titanium powder mixtures with carbon nanotubes in a planetary ball mill, on a possibility of realization of the self-propagating interaction of reagents in the mode of dynamic thermal explosion and influence on phase composition and morphology of the formed products.

\section{EXPERIMENTAL}

The procedure for preparing initial mixtures of hydrocarbon nanotubes with titanium was as follows: carbon nanotubes were treated in alcohol for 10 minutes in an ultrasonic low-frequency disperser UZDN1U4.2. To the obtained alcohol suspension was added a predetermined amount of titanium powder, and thereafter the sample was dried in a furnace at $40^{\circ} \mathrm{C}$ for 1 hour. Thereafter, to improve the homogeneity of the mixture a sample was triturated in a porcelain mortar. The obtained mixture of initial reagents was exposed to mechanical activation. Mechanical activation of the reaction mixtures was carried out in a planetary ball mill AGO-2 with water cooling ${ }^{28}$. For prevention of oxidation during mechanoactivation, argon was used for filling drums with samples. After mechanoactivation, the samples were unloaded from the drums in a box with an argon atmosphere. The activation duration was varied from 1 to $11 \mathrm{~min}$.

The samples obtained by mechanoactivation were used to conduct a thermal explosion. The scheme of the experimental setup for carrying out the reaction in the regime of a dynamic thermal explosion in an argon atmosphere is shown in Figure-1. The main structural element of the installation is a specialized reactor ${ }^{29-}$

${ }^{31}$, created on the basis of an induction crucible electric furnace ILT-0.0005/1.0 - 22 - I1. In this furnace, a copper tubular, water-cooled inductor heats the graphite crucible. An alundum crucible with a sample is inserted into the crucible. The mass of the sample was $35 \mathrm{~g}$. The samples were compacted to a relative density of $0.35-0.4$. The furnace power is $1 \mathrm{~kW}$. The frequency of the inductor current is $22 \mathrm{kHz}$. The maximum heating rate of the sample in this installation in an argon atmosphere is $60^{\circ} \mathrm{C} / \mathrm{min}$. The maximum heating temperature is $1100^{\circ} \mathrm{C}$. The heating rate and temperature of the furnace were monitored using a furnace control unit. To record thermograms, tungsten-rhenium thermocouples (VAR 5/BP 20) with a diameter of $100 \mu \mathrm{m}$ were used. The signal from the thermocouple came to the analogdigital converter LA - 2USB - 14 and further to the computer. Before heating the samples and after a thermal explosion, the reactor was purged with argon. In preliminary experiments, it was found that in this case oxidation of the samples does not occur. The rate of sample heating was chosen to be constant $\left(40^{\circ} \mathrm{C} / \mathrm{min}\right)$.

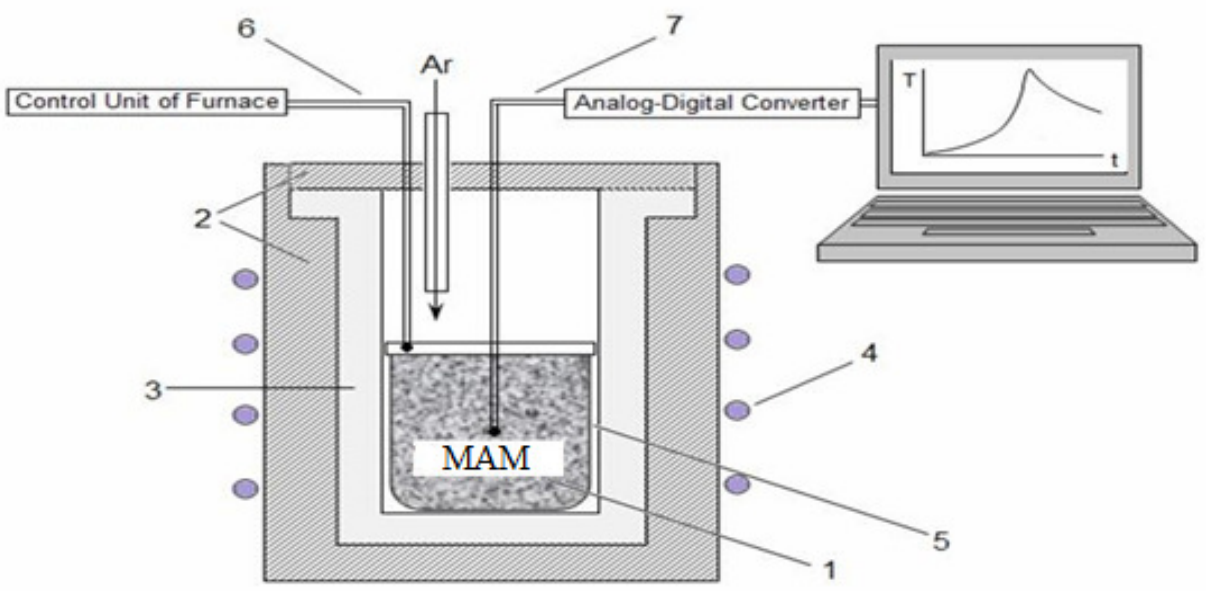

Fig.-1: The scheme of the experimental setup: 1 - mechanically activated mixture (MAM), 2 - ceramic block, 3 - graphite crucible, 4 - inductor, 5 - alundum crucible, 6 - furnace control block, 7 - furnace thermocouple, 8 tungsten-rhenium thermocouple BP5/BP20, 9 - ADC, 10 - computer 
RASĀYAN J. Chem.

Vol. 11 | No. 1 |324 - 330 | January - March | 2018

Reaction mixtures after mechanoactivation and products of a thermal explosion were studied by X-ray phase analysis (XRD) and scanning electron microscopy. Radiographs were taken on the DRON-4,0 and D8ADVANCE (Bruker) diffractometers using $\mathrm{Cu} \mathrm{K \alpha}$ radiation. Electron microscopy was performed on scanning microscopes TM-1000, S-3400 N (Hitachi), Carl Zeiss EVO50 XVP (X-Act).

\section{Study of synthesized samples of CNT with titanium}

\section{RESULTS AND DISCUSSION}

According to the literature data-6,9,14,32-41 the microstructure and morphology of the initial reagents significantly change during mechanical processing in planetary mills. In mixtures of brittle substances, grinding mainly occurs, and in the mixtures of ductile metals, or mixtures of plastic metals with amorphous carbon or boron, mechanocomposites are formed. Mechanocomposites are fairly large formations ranging in size from tens to hundreds of microns, and in some compositions and larger, up to millimeter-sized. The grain size of the original components in these composites decreases to nanometer values.

Figure-2 shows micrographs of a mixture of the initial components obtained by the above-described procedure. In the starting mixture, the particles have different shapes and sizes (Fig.-2a), and carbon nanotubes cover the particles of titanium powder (Fig.-2b).

As a result of the study of changes in the morphology of mechanically activated samples, it has been established that after 2 min. mechanical activation, mechanocomposites of various sizes of irregular shape are formed (Fig.-3a), some of which have a plate-like shape (Fig.-3b). After 2 min. on the surface of titanium particles there are no already carbon nanotubes, which indicates their incorporation into the volume of mechanocomposites.

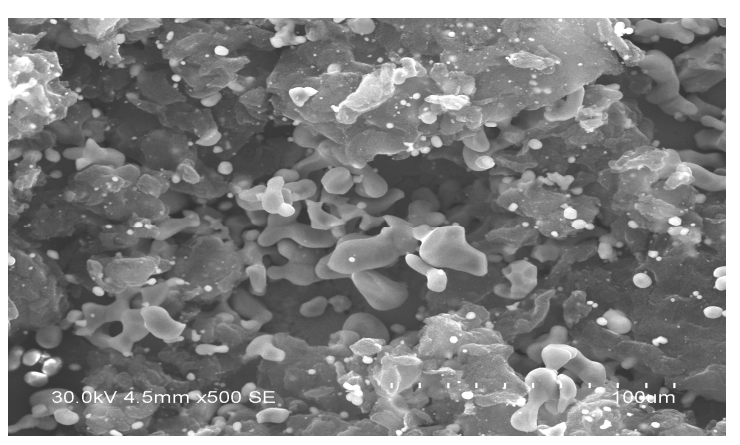

a

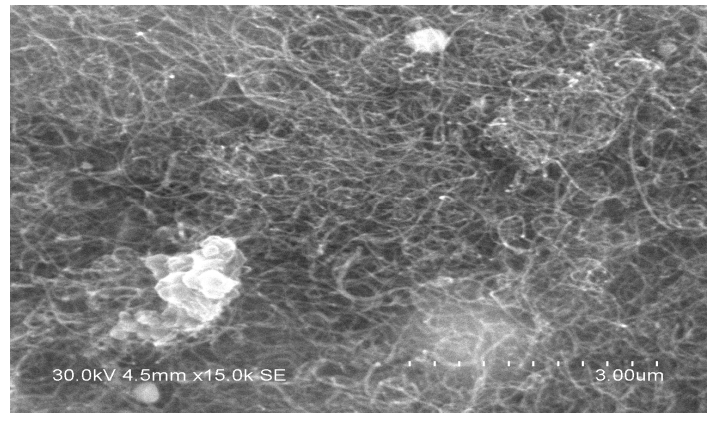

b

Fig.-2: Microphotographs of an initial mixture: (a) $\mathrm{Ti}+4 \% \mathrm{CNT}$, (b) surface of a separate particle of a titanium

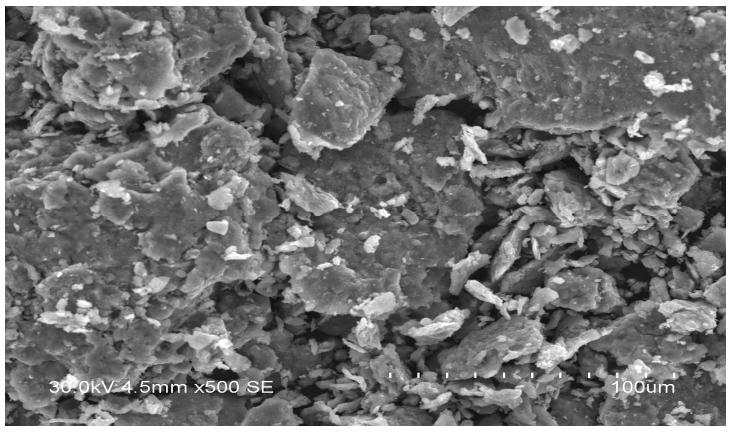

a

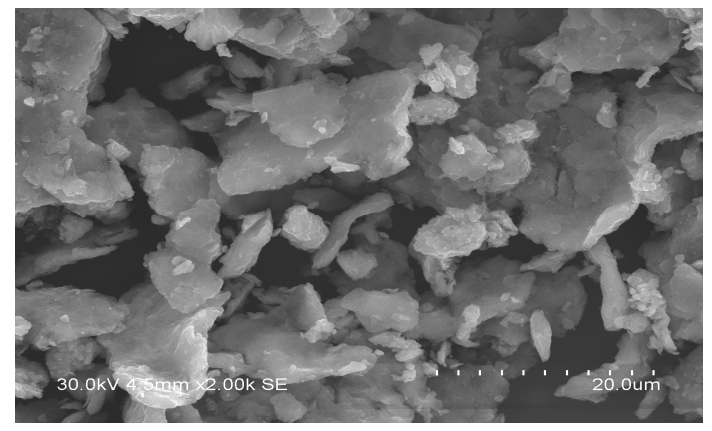

b

Fig.-3: Micrographs of a sample of $\mathrm{Ti}+4 \% \mathrm{CNT}$ after 2 min of mechanoactivation at different magnification 
With an increase in the duration of mechanoactivation, the larger mechanocomposites take on a rounded form, and the formation of loose agglomerates starts from smaller ones (at 4 to $5 \mathrm{~min}$. of mechanoactivation). Later, the number of such agglomerates increases, their density increases.

The results of X-ray phase analysis showed that after $1.5 \mathrm{~min}$ of mechanoactivation, in addition to the titanium lines, weak lines of $\mathrm{TiC}$ are also present on the roentgenogram. This indicates that partial formation of the primary products of the interaction of CNT with titanium begins in the mill drums. With increasing mechanoactivation time, the intensity and width of these TiC lines increase (Fig.-4).

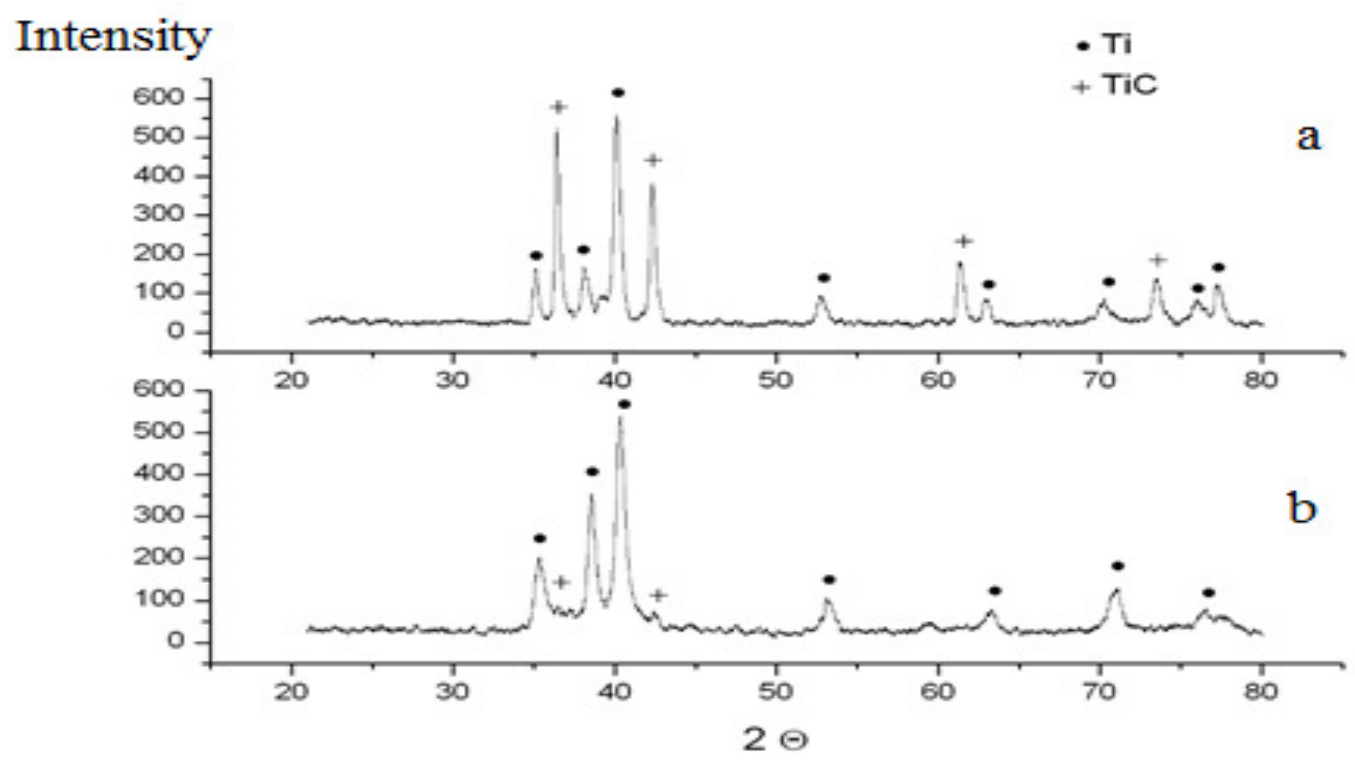

Fig.-4: X-ray patterns of $\mathrm{Ti}+4 \mathrm{wt}$ \% $\mathrm{CNT}$ (a) products of thermal explosion after 2 min. mechanoactivation, (b) sample composition $\mathrm{Ti}+4$ wt. \% CNT after 2 min. mechanoactivation

\section{Study of thermal explosion in $\mathrm{Ti}+4 \%$ CNT samples}

The thermal explosion in activated samples of $\mathrm{Ti}+4 \% \mathrm{CNT}$ composition can be realized starting from 1.5 min of mechanoactivation. At $346^{\circ} \mathrm{C}$, a continuous heat release begins to $573^{\circ} \mathrm{C}$, and then a sharp increase in temperature is observed up to the maximum value of the thermal explosion, which is equal to $1050^{\circ} \mathrm{C}$ (Fig.-5). When shorter mechanical activation times, at $1 \mathrm{~min}$. the thermal explosion is not realized, and only a weak heat release is observed beginning at a temperature of $350^{\circ} \mathrm{C}$, and the temperature rises to $770^{\circ} \mathrm{C}$.

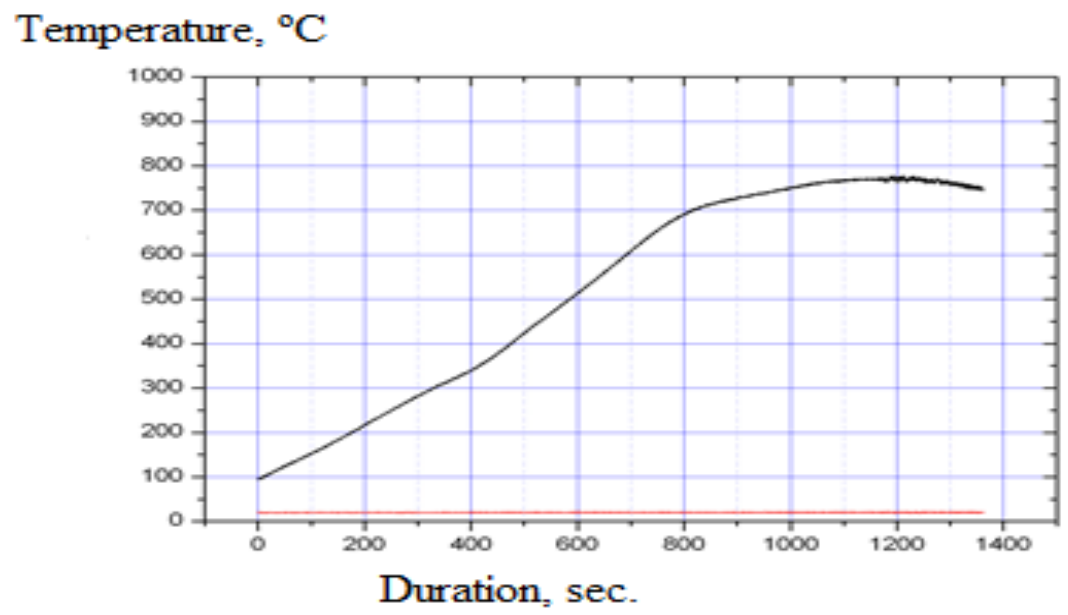

Fig.-5: Thermogram of heat release in the sample after 1 min. of preliminary mechanoactivation 
RASĀYAN J. Chem.

Vol. 11 | No. 1 |324 - 330 | January - March | 2018

It is found that the nature of a thermal explosion varies with the increase in the time of preliminary mechanical activation. After 3 min. of mechanoactivation in the sample at $346^{\circ} \mathrm{C}$, the preliminary smooth heat release starts at a temperature of $441^{\circ} \mathrm{C}$, and a thermal explosion occurs, the maximum temperature is $930^{\circ} \mathrm{C}$. With an increase in the time of mechanical activation from 1.5 to 7 min., the region with a smooth heat release decreases practically to zero.

It is established that the phase composition of the products of the thermal explosion of the system under investigation is practically independent of the time of preliminary mechanical activation. If the mechanical activation time is increased from 1.5 to $7 \mathrm{~min}$., the products of the thermal explosion are titanium and titanium carbide (Fig.-6, Fig.-7).

\section{CONCLUSION}

The result of the study was the preparation of various samples of powdered mixtures of titanium with carbon nanotubes subjected to preliminary mechanical activation. Synthesized samples were used to study the possibility of realizing the self-propagating interaction of reagents in the regime of a dynamic thermal explosion. The time of mechanoactivation varied from 1.5 to $8 \mathrm{~min}$. After 2 minutes. mechanical activation, mechanocomposites of various sizes of irregular shape are formed, some of which are lamellar, there are no carbon nanotubes on the surface of titanium particles, which indicates their incorporation into the volume of mechanocomposites. The results of X-ray phase analysis showed that the partial formation of the primary products of interaction of carbon nanotubes with titanium began already in the mill drums. With increasing mechanoactivation time, the intensity and width of the TiC lines increase. The thermal explosion in activated samples of composition carbon nanotubes Ti+4\% starts from $1.5 \mathrm{~min}$ of mechanoactivation. The nature of the thermal explosion varies with the increase in the time of preliminary mechanical activation. After 3 minutes of mechanoactivation in the sample at $346^{\circ} \mathrm{C}$, the preliminary smooth heat release begins at a temperature of $441^{\circ} \mathrm{C}$, and a thermal explosion occurs, the maximum temperature is $930^{\circ} \mathrm{C}$. At an increase in the time of mechanical activation from 1.5 to $7 \mathrm{~min}$, the region with a smooth heat release decreases practically to zero. The phase composition of the products of the thermal explosion of the system under investigation is practically independent of the duration of the preliminary mechanical activation. When the mechanical activation time is increased from 1.5 to $7 \mathrm{~min}$., the products of the thermal explosion are titanium and titanium carbide.

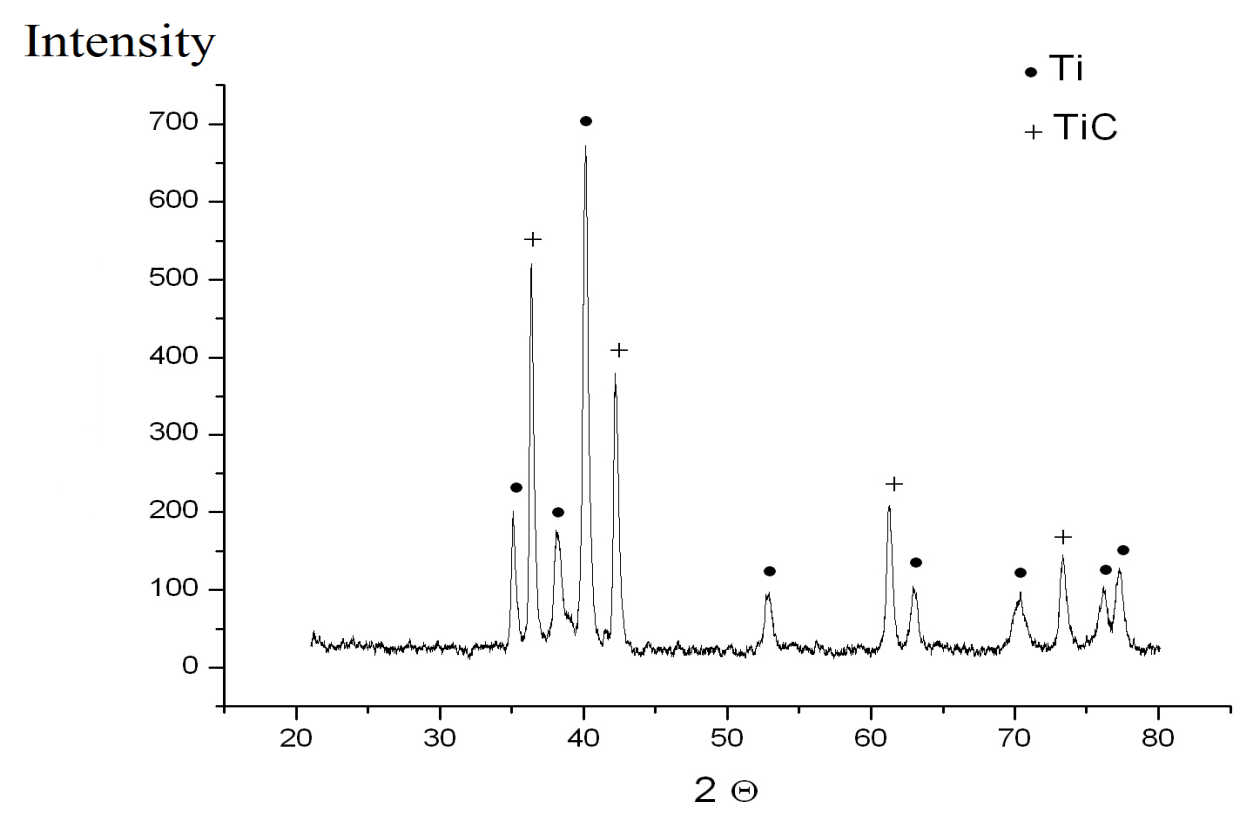

Fig.-6: X-ray diffraction patterns of products of a thermal explosion after 1.5 min mechanical activation 
RASĀYAN $J$. Chem.

Vol. 11 | No. 1 |324 - 330 | January - March | 2018

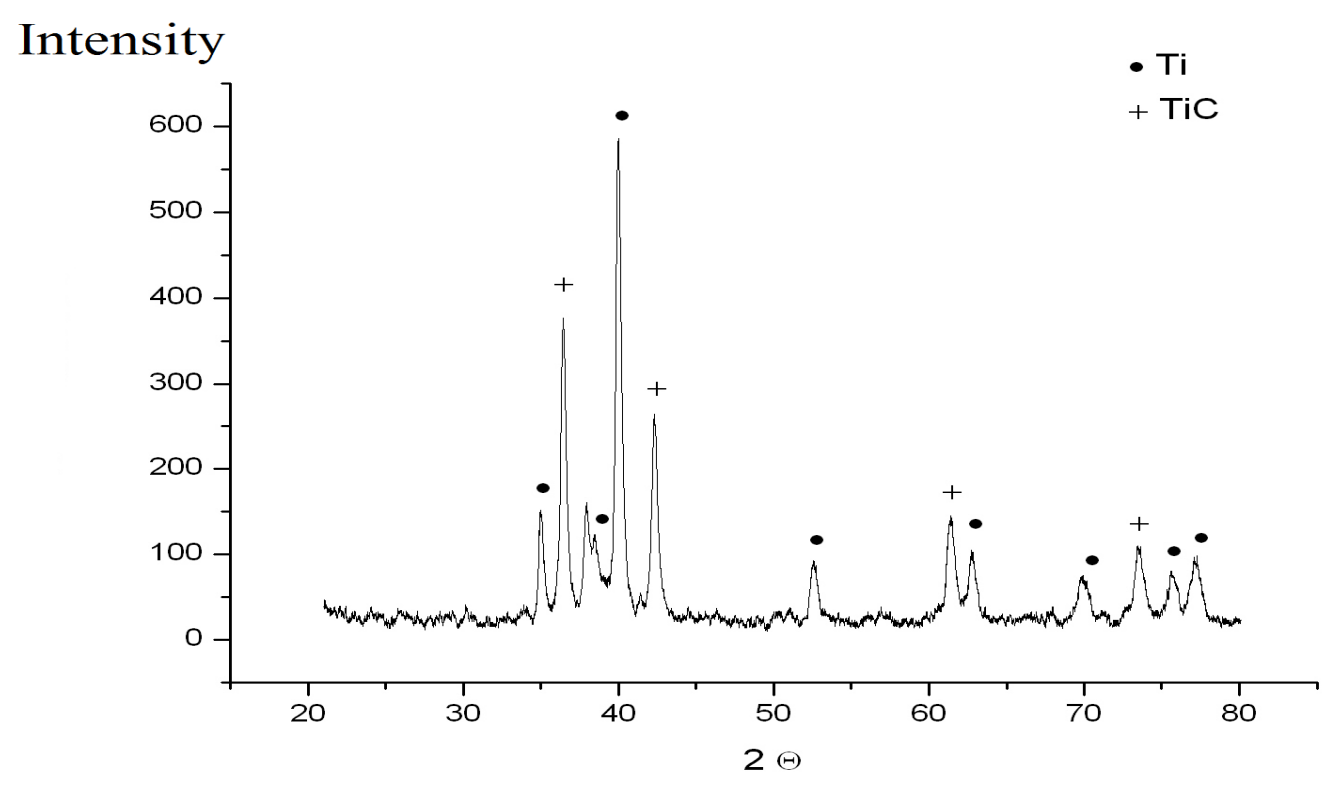

Fig.-7: X-ray diffraction patterns of products of a thermal explosion after 4 min. mechanical activation

\section{REFERENCES}

1. M.M.J. Treacy, T.W. Ebbesen and J.M. Gibson, Nature, 381, 678(1996).

2.Z.A. Mansurov, M.I. Tulepov, Y.V. Kazakov, S.E. Gabdrashova, L.R. Sassykova, D.A. Baiseitov, S. Tursynbek and A. Dalton, Int. J. Chem. Sci., 15(3), 150(2017).

3. Y.A. Aubakirov, L.R. Sassykova, A.M. Nalibayeva, K. Dossumov, Z.K. Tashmukhambetova, A.

S. Zhumakanova, A.K. Zhussupova and N.K. Zhakirova, Oriental J Chem, 33(6), 3130(2017).

4. W.A. Curtin and B.W. Sheldon, Mater. Today, 7 (11), 44(2004).

5. X. Sun, Y. Han, S. Cao, P. Qiu and W. Lu, J. Mat. Sci.\& Tech., 33(10), 1165(2017).

6. D.A. Baiseitov, Sh.E. Gabdrashova, A.N. Magazova, O. Dalelkhanuly, Zh.B. Kudyarova, M.I.

Tulepov, L.R. Sassykova and Z.A. Mansurov, Int. J. Chem. Sci., 14(1), 244(2016).

7. R. Sivakumar, S.Q. Guo, T. Nishimura and Y. Kagawa, Scr. Mater., 56, 265(2007).

8. B. Chen, S.F. Li, H. Imai, L. Jia, J. Uneda and M. Takahashi, Compos. Sci. Technol., 113, 1(2015).

9. P.C. Tsai and Y.R. Jeng, Compos. Sci. Technol., 79, 28(2013).

10. S.J. Yoo, S.H. Han and W.J. Kim, Carbon, 61, 487(2013).

11. S.J. Yoo, S.H. Han, W.J. Kim, Scr. Mater., 67, 129(2012).

12. C.D. Li, X.J. Wang, W.Q. Liu, K. Wu, H.L. Shi and C. Ding, Mater. Sci. Eng., A 597, 264(2014).

13. H. Fukuda, K. Kondoh, J. Umeda and B. Fugetsu, Compos. Sci. Technol., 71, 705(2011).

14. J. Stein, B. Leczowski, N. Frety and E. Anglaret, Carbon, 50, 2264(2012).

15. W.J. Kim and S.H. Lee, Compos. Part A Appl. Sci. Manuf., 67, 308(2014).

16. S.J. Yoo, S.H. Han and W.J. Kim, Scr. Mater., 68, 711(2013).

17. B. Chen, S.F. Li, H. Imai, L. Jia, J. Uneda and M. Takahashi, Micron, 69, 1(2015).

18. J.Y. Hwang, B.K. Lim, J. Tiley, R. Banerjee and S.H. Hong, Carbon, 57, 282(2013).

19. S. Suarez, E. Ramos-Moore, B. Lechthaler and F. Mücklich, Carbon, 51, 404(2013).

20. S. Suarez, F. Lasserre and F. Mücklich, Mater. Sci. Eng., A 587, 381(2013).

21. L.R. Sassykova, A.M. Nalibayeva and Sh.A. Gil'mundinov, Bulgarian Chemical Communications, 49(3), 583(2017).

22. S.F. Li, B. Sun, H. Imai, T. Mimoto and K. Kondoh, Compos. Part A-Appl. Sci. Manuf., 48, 57(2013).

23. K. Kondoh, T. Threrujirapapong, H. Imai, J. Umeda and B. Fugetsu, Compos. Sci. Technol., 69, 1077(2009). 
RASĀYAN $J$. Chem.

Vol. 11 | No. 1 |324 - 330 | January - March | 2018

24. K. Kondoh, T. Threrujirapapong, J. Umeda and B. Fugetsu, Compos. Sci. Technol., 72 (8), 1291(2012).

25. S. Sendil Velan, K.B. Jeyachandran and K. Bhaskar, SAE Technical Paper, 2001-01-2000, 2001.

26. S. Sendilvelan and K. Rajan, Rasayan J. Chem., 10(1),190(2017).

27. K. Bhaskar, L.R. Sassykova, M. Prabhahar and S. Sendilvelan, International Journal of Mechanical and Production Engineering Research and Development, 8(1), 399(2018).

28. M.A. Korchagin, T.F. Grigorieva, B.B. Bokhonov, M.R. Sharafutdinov, A.P. Barinova and N.Z. Lyakhov, Combustion and Explosion Physics, 39 (1), 51(2003).

29. D. Baiseitov, M.Tulepov, L. Sassykova, Sh.Gabdrashova, K. Kudaibergenov and Z. Mansurov, Revue Roumaine de Chimie, 62(3), 249(2017).

30. M.A. Korchagin, T.F. Grigorieva, B.B. Bokhonov, M.R. Sharafutdinov, A.P. Barinova and N.Z. Lyakhov, Combustion and Explosion Physics, 39 (1), 60(2003).

31. V.Yu. Filimonov, M.A. Korchagin, I.A. Ditenberg, A.N. Tyumentsev and N.Z. Lyakhov, Powder Technology, 335, 606(2013).

32. V.Yu.Filimonov, M.A.Korchagin and N.Z. Lyakhov, Intermetallics, 19, 833(2011).

33. M.A. Korchagin and N.Z. Lyakhov, Chemical Physics, 27 (1), 73(2008).

34. D.A. Baiseitov, M.I. Tulepov, S.Tursynbek, L.R. Sassykova, M.Nazhipkyzy, Sh.E.Gabdrashova, Y.V.Kazakov, I.O. Pustovalov, F.Y.Abdrakova, Z.A.Mansurov and A.B. Dalton, Rasayan J. Chem., 10(2), 344(2017).

35. M. I. Tulepov, D.A. Baiseitov, Sh. E. Gabdrashova, L. R. Sassykova, Y. V. Kazakov, S. Tursynbek, K Toshtay, I. O. Pustovalov, F.Y. Abdrakova, Z. A. Mansurov and A. B. Dalton, Rasayan J. Chem., 10(4), 1145(2017).

36. S. Sendilvelan and K. Bhaskar, Oriental J Chem, 33(4), 2111(2017).

37. L. Sassykova, A. Nalibayeva, Y. Aubakirov, Zh.Tashmukhambetova, U. Otzhan, N. Zhakirova and M. Faizullaeva, Oriental J Chem, 33(4), 1941(2017).

38. D.A. Baiseitov, Sh.E. Gabdrashova, A.K. Akylbai, O. Dalelkhanuly, Zh.B. Kudyarova, L.R. Sassykova, M.I. Tulepov and Z.A. Mansurov, Int. J. Chem. Sci., 14(1), 261(2016).

39. D. A. Baiseitov, M.I. Tulepov, L.R. Sassykova, Sh.E. Gabdrashova and Z.A. Mansurov, Bulgarian Chemical Communications, 49(3), 600(2017).

40. A.S. Rogachev, N.F. Shkodich, S.G. Vadchenko, F. Baras, R. Chassagnon, N.V. Sachkova and O.D. Boyarchenko, International Journal of Self-Propagating High-Temperature Synthesis, 22(4), 210(2013).

41. M.A. Korchagin and D.V. Dudina, Combustion and Explosion Physics, 43 (2), 58(2007).

[RJC-2017/2017] 